\title{
Morphological features in aluminum nitride epilayers prepared by magnetron sputtering
}

\author{
Sebastian Stach ${ }^{1}$, Dinara Dallaeva ${ }^{2}$, ŞTefan Ţălu ${ }^{3 *}$, PaVel Kaspar $^{2}$, \\ PAVEl TOMÁNeK ${ }^{2}$, Stefano GiovanzanA ${ }^{4}$, Lubomír GRMElA ${ }^{2}$ \\ ${ }^{1}$ University of Silesia, Faculty of Computer Science and Materials Science, Institute of Informatics, \\ Department of Biomedical Computer Systems, ul. Będzińska 39, 41-205 Sosnowiec, Poland \\ ${ }^{2}$ Brno University of Technology, Faculty of Electrical Engineering and Communication, Physics Department, Technická 8 , \\ 61600 Brno, Czech Republic \\ ${ }^{3}$ Technical University of Cluj-Napoca, Faculty of Mechanical Engineering, Department of AET, Discipline of Descriptive \\ Geometry and Engineering Graphics, 103-105 B-dul Muncii St., Cluj-Napoca 400641, Cluj, Romania \\ ${ }^{4}$ University of Milan-Bicocca, 20125 Milano, Italy
}

The aim of this study is to characterize the surface topography of aluminum nitride (AlN) epilayers prepared by magnetron sputtering using the surface statistical parameters, according to ISO 25178-2:2012. To understand the effect of temperature on the epilayer structure, the surface topography was investigated through atomic force microscopy (AFM). AFM data and analysis of surface statistical parameters indicated the dependence of morphology of the epilayers on their growth conditions. The surface statistical parameters provide important information about surface texture and are useful for manufacturers in developing AlN thin films with improved surface characteristics. These results are also important for understanding the nanoscale phenomena at the contacts between rough surfaces, such as the area of contact, the interfacial separation, and the adhesive and frictional properties.

Keywords: aluminum nitride epilayer; atomic force microscopy; magnetron sputtering; substrate; surface roughness

(C) Wroclaw University of Technology.

\section{Introduction}

As opposed to bulk material thin layers properties strongly depend on the surface condition. Morphological features and associated with them statistical parameters (volume and spatial) define surface profile of films topography and characterize their quality. Micro- and nano-asperities evaluation is important in heterostructures preparation. Topography of the films also influences the surface of the deposited thin contact layers.

Aluminum nitride is an $\mathrm{A}_{3} \mathrm{~B}_{5}$ group wide band gap $(6.3 \mathrm{eV})$ semiconductor [1] with a wurtzite crystal structure. Its experimental crystal lattice parameters are: $\mathrm{a}=3.11 \AA, \mathrm{c}=4.98 \AA$, yielding a relaxed c/a ratio of 1.6 [2]. There is a considerable ionic component in AlN bonding because of

*E-mail: stefan_ta@yahoo.com electronegativities (1.6 and 3.0) of $\mathrm{Al}$ and $\mathrm{N}$ atoms. The atomic radii are $1.25 \AA$ for $\mathrm{Al}$ and $0.70 \AA$ for $N$ [3]. One aluminum atom is surrounded by four nitrogen atoms, making up a distorted tetrahedron with three bonds and one bond in the direction of the c-axis [4]. The electronegativities of $\mathrm{Al}$ and $\mathrm{N}$ are very different: 1.6 and 3.0, respectively, and so there is a significant ionic component to the bonding in AlN. Other properties of AlN are: direct band gap $(6.2 \mathrm{eV})$, thermal conductivity $\left(285 \mathrm{~W} \cdot \mathrm{m}^{-1} \cdot \mathrm{K}^{-1}\right)$, coefficient of thermal expansion ( 4 to $5 \times 10^{-6} \mathrm{~K}^{-1}$ ), refractive index $(1.8$ to 2.2) and dielectric constant (8.5) [4].

Prominent features of aluminum nitride make this material one of the most desirable in modern electronics. It is characterized by interesting tribological [5] properties, high value of hardness and high thermal conductivity, moderate piezoelectricity, low dielectric and acoustic losses [6], high 
resistance to temperature and stability in corrosive medium [7], good heat dissipation [8], high dielectric constant, moderately high electromechanical coupling coefficient [9], low coefficient of thermal expansion [4], high elastic stiffness [2], non-toxicity [10], electrical reliability [11], light weight [12], high fusion temperature [13], high refractive index, transparence in visible light [14]. All these characteristics in combination with large optical band gap make AlN suitable for applications in high power and high frequency devices, surface acoustic wave filters, insulating [7], passivating, cladding layers [15] and optical devices (blue light emitting diodes, short wavelength lasers, ultraviolet light detectors [16], compact disks, laser diodes, phase shift lithography masks, AlN/GaN multilayer devices [17], for growth of GaN layers on $\mathrm{Al}_{2} \mathrm{O}_{3}$ and on $6 \mathrm{H}-\mathrm{SiC}$, which are also of interest as perspective materials), electroluminescent applications over a wide wavelength range [18], acoustic-optic devices.

Oxidized AlN can substitute traditional passivating films, such as silicon nitride and silicon oxide, at p-type solar cells [13], selective detectors [19], field emitters for flat panel displays, highspeed transistors [20]. As noted Auger et al. [7], it can be applied as an intermediate buffer layer for optical and electronic devices and for further fabrication of heterostructures.

AlN thin films can be applied for metaloxide-semiconductor field-effect transistor [21], CMOS technologies, microelectromechnical and microoptomechanical systems fabrication [22, 23], electronic packaging, waveguides, sensors [24], electro-acoustic applications (microactuators, filters, resonators, acoustic modulators, surface acoustic wave devices) $[6,11,25]$. There are a lot of methods for thin films fabrication, such as pulsed laser deposition, reactive molecular beam epitaxy, vacuum arc/cathodic arc deposition, DC/RF reactive sputtering, ion beam sputtering, metal-organic chemical vapor deposition etc. [26].

The way of AlN formation is determined by subsequent applications. Magnetron sputtering is one of physical thin film deposition techniques and is characterized by low-temperature deposition, ease of synthesis, low cost, nontoxicity, good quality films with a fairly smooth surface [4]. Magnetron sputtering is employed in thin films production for different applications in microelectronics, partially integrated circuits and in optoelectronics. By changing of process parameters (bias-voltage, substrate temperature, gas mixture, pressure, sputter current, applied voltage [27]) it is possible to control the film microstructure and its mechanical, optical, and electrical properties [28]. This method allows processing the substrate and film surfaces, such as etching, deposition, annealing, and ion implantation [29].

By magnetron sputtering it is possible to fabricate hard, wear-resistant, low friction, corrosion resistant, decorative coatings and coatings with specific optical, or electrical properties [30], thin film sensors, photovoltaic thin films (solar cells), metal cantilevers and interconnects [31]. The critical factor of piezoelectric AlN thin film is its crystal orientation and morphology [4].

Low-cost AlN-on-silicon photonic circuits are excellent substitutes for complementary metaloxide-semiconductor-compatible photonic circuits for building new functional optomechanical devices that are free from carrier effects [9].

The studies of AlN thin film could be divided into the investigations which emphasize chemical and physical properties (mechanical, electrical, magnetic) $[6,9,17,21,22]$, analysis of the films structure $[4,7,12,15,16,19,23-25,32]$ and combined, showing the dependences of the properties on the films morphology $[2,11,13,14,26,33-$ 35]. The structure of the thin films can utterly differ from the structure of bulk material and have different structural perfection.

The surface features, such as defect concentration, are very important in the case of thin films. Some properties of thin films strongly depend on the structure. The study was carried out on the applicability of statistical parameters for aluminum nitride thin films characterization. This analysis represents instructive information for thin films manufacturing and processing. 


\section{Materials and methods}

\subsection{Materials}

The processes used for aluminum nitride formation by magnetron sputtering include dry etching, ion implantation of the substrate and sputtering of the target. We used magnetron sputtering of aluminum target for thin films fabrication since this method is compatible to semiconductor processes. The foundation of this method is sputtering of target material (high-purity aluminum) by ions of working gas in plasma of glow discharge. Argon $\left(\mathrm{Ar}_{2}\right)$ was used for target sputtering. Plasma occurs in vacuum after applying high voltage between cathode-target and anode and acts as a conducting medium. The essential constituents of the process are cathode, anode and magnetic system for plasma confinement near the cathode surface. High sputtering rate and accuracy of the composite recurrence are the advantages of magnetron sputtering. The pressure in the working chamber was 3 to $7 \times 10^{-2} \mathrm{~Pa}$, current density of discharge 5 to $7 \times 10 \mathrm{~A} / \mathrm{m}^{2}$. These parameters define the rate of condensation which consequently influences the structure of the films. The films can be obtained by sputtering of polycrystalline aluminum nitride target, but it is possible to control thin films structure by gas composition in the chamber. The nitrogen gas was used for creation of work ambience and to accomplish nitrogen incorporation in AlN fabrication. Magnetron sputtering device allows fabrication of materials with good stoichiometry. This method was described by Dallaeva et al. [36]. Aluminum nitride films were deposited on sapphire substrates $\left(\mathrm{Al}_{2} \mathrm{O}_{3}\right)$ at different substrate temperatures. Monocrystalline sapphire is one of the hardest oxides, with high hardness at high temperatures, good thermo-physical properties and it is optically transparent in the visible light to near-infrared region [36].

The substrates were cleaned by dry etching in order to remove the traces of polishing and then the nitridization of near surface area was carried out. This helped to create the buffer layer between $\mathrm{Al}_{2} \mathrm{O}_{3}$ and $\mathrm{AlN}$. The substrate temperature has a strong impact on the growth behavior [27] and morphology of the films. The temperature of the substrate is a very important parameter because its changing causes a change in energetic barrier near the substrate surface. In addition, it influences the character of film growth: sizes of nucleolus and rate of nucleation.

We obtained the films at three temperatures $(1000 \mathrm{~K}, 1300 \mathrm{~K}$ and $1500 \mathrm{~K})$ of the substrate. The film becomes smooth at low width and it consists of large number of small nuclei. These islands are three-dimensional (3-D) and they have noticeable sizes in the normal direction to growth plane [37].

\subsection{Methods}

The films have been characterized by atomic force microscopy (AFM) and scanning electron microscopy (SEM) in order to describe the 3-D growth character of thin films and to investigate their surface morphology. 3-D surface roughness of the epilayers was investigated by atomic force microscope Ntegra Prima (NT-MDT, Russian Federation) in semi-contact mode.

Cantilevers, model NSG01 DLC (AFM "Golden" Silicon Probes) [38] with the following nominal specifications: resonant frequency $150 \mathrm{kHz}$, force constant $5.1 \mathrm{~N} / \mathrm{m}$, length $125 \mu \mathrm{m}$, width $30 \mu \mathrm{m}$ and thickness $2 \mu \mathrm{m}$, were used. The tip specifications were as follows: tetrahedral shape, height $14 \mu \mathrm{m}$, curvature radius $6 \mathrm{~nm}$, and cone angle at the apex $7^{\circ}$ to $10^{\circ}$ [38].

All measurements were performed in the same room, at room temperature $(298 \pm 1 \mathrm{~K})$ and $(50 \pm 1 \%)$ relative humidity. The measurements were repeated four times for each sample on different reference areas, to validate the reproducibility of these features.

\subsection{Surface characterization using quan- titative parameters}

The 3-D surface characteristics are highly complex and their understanding plays a determinant role in recognizing physico-chemical interactions and interfacial properties at the nanometer range, involved in manufacturing process [3941]. Surface texture is the repetitive or random deviation from the nominal surface that forms the 
3-D topography of the surface and includes: roughness (nano-and microroughness); waviness (macroroughness); lay and flaws [39].

The 3-D surface roughness of thin films can be described using the classical descriptive approach [42-47]. Detailed surface characterization of the thin films was obtained using six quantitative parameters (height, functional, spatial, hybrid, functional (volume) and feature parameters), according to ISO 25178-2:2012 [48, 49].

\subsection{Statistical analysis}

Statistical analyses were performed using the GraphPad InStat version 3.20 computer software package (GraphPad, San Diego, CA, USA) [50]. The Kolmogorov-Smirnov test was used to assess the normal distribution of quantitative variables. Comparisons among different areas within the same sample were performed using independent samples T-test. When statistical significance was found, the difference between two groups was further compared using the Mann-Whitney U test. Differences with a $\mathrm{P}$ value of 0.05 or less were considered statistically significant.

\section{Results}

The representative two-dimensional (2-D) microtopographic images of AlN layers on the sapphire substrate obtained at $1000 \mathrm{~K}, 1300 \mathrm{~K}$ and $1500 \mathrm{~K}$, for a scanning square area of $5 \mu \mathrm{m} \times 5 \mu \mathrm{m}$, are shown in Fig. 1.

As known, there are several possible structures of AlN crystals: granular, worm-like, and a columnar surface of grains [23]. In our case of cleaned and nitridized sapphire substrate, the columnar structure has been expected. It has been expected that the grains are oriented along the growth direction [34].

The heterostucture of (0001)AlN /(0001) $\mathrm{Al}_{2} \mathrm{O}_{3}$ was studied by scanning electron microscopy (SEM) with the SEM system (FEI Quanta 200). This measurement showed the occurrence of AlN film on the $\mathrm{Al}_{2} \mathrm{O}_{3}$ substrate. In the cross-sectional image (Fig. 2) there are crystalline columnar grains of AlN. Their tops are flat.

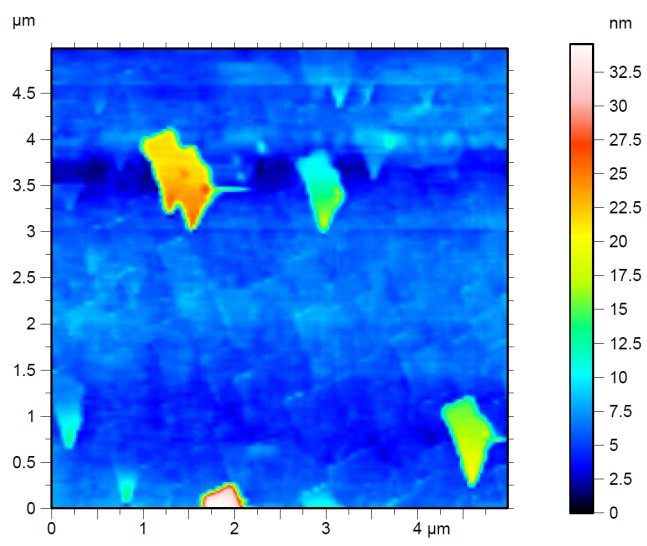

(a)

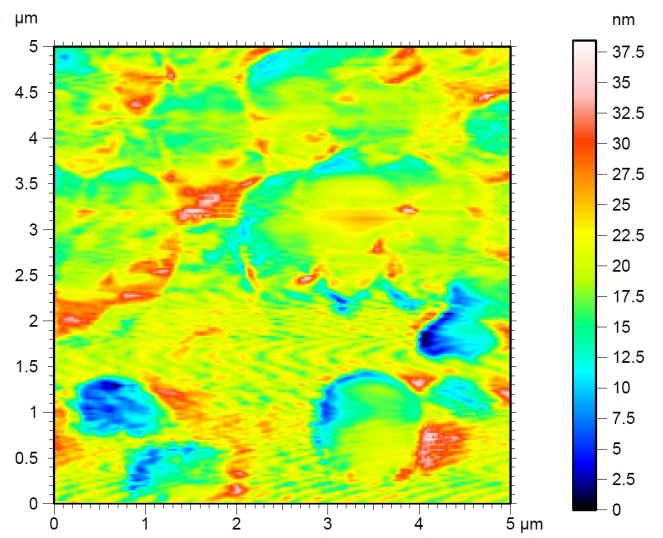

(b)

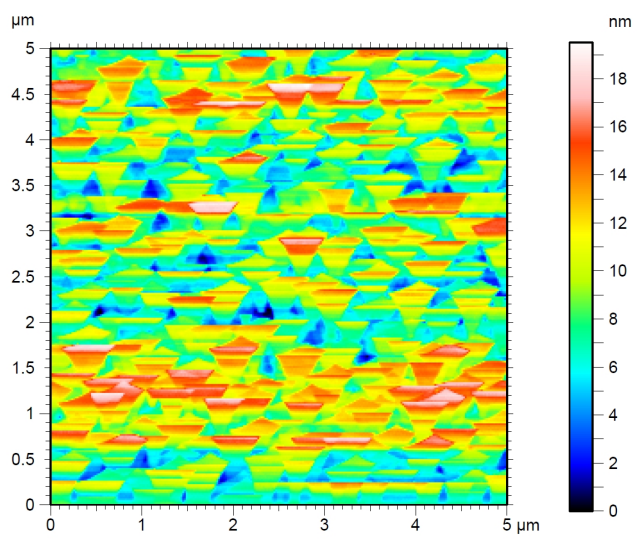

(c)

Fig. 1. Representative 2-D microtopographic AFM images of AlN epilayers on sapphire substrates obtained at: a) $1000 \mathrm{~K}$, b) $1300 \mathrm{~K}$ and c) $1500 \mathrm{~K}$; scanning square area of $5 \mu \mathrm{m} \times 5 \mu \mathrm{m}$; vertical range of the displayed data $(\mathrm{nm})$ and the color bars are shown on the right side of the AFM images. 


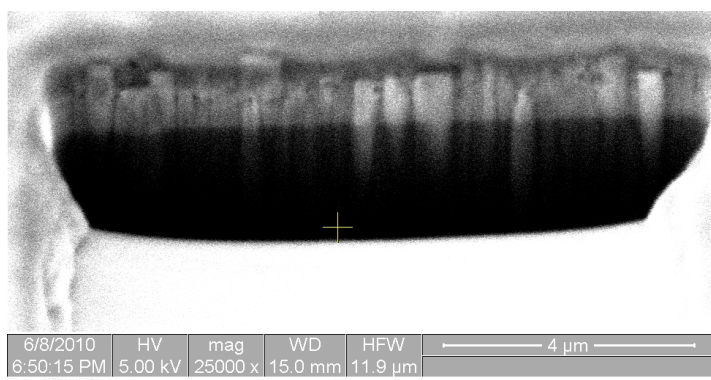

Fig. 2. A SEM image of the AlN epilayer on the sapphire substrate in cross-section.

The graphical study of volume parameters (surface): Vmp, Vvc, Vmc and Vvv based upon the Abbott curve calculated on the surface associated with Fig. 1, is shown in Fig. 3.

The curve of material share provides important information about the condition of the surface in terms of its operational suitability. It is known that for the optimal functionality of the surface, it is required to be progressive or progressive-regressive.

The graphical study of Sk parameters associated with Fig. 1 is shown in Fig. 4.

The peak count histograms associated with Fig. 1 are shown in Fig. 5.

Qualitative control of the image includes both measuring of the surface features and its distribution along the surface. The data in Fig. 5 indicate the uniform growth of surface feature sizes with the increasing of substrate temperature.

Height-height correlation function provides considerable information about topography condition (such as estimation of correlation areas, sizes of grains and holes, and the character of their distribution). The height-height correlation functions associated with Fig. 1 are shown in Fig. 6.

Lateral force mode of AFM provides edgeprecision scanning of the surface for feature emphasis. Fig. 7 allows visual estimation of the surface appearance (small regular lines are the scanning artefacts as no filter was applied in order to observe the real objects shape).

A summary of the statistical parameters results is presented in Table 1.

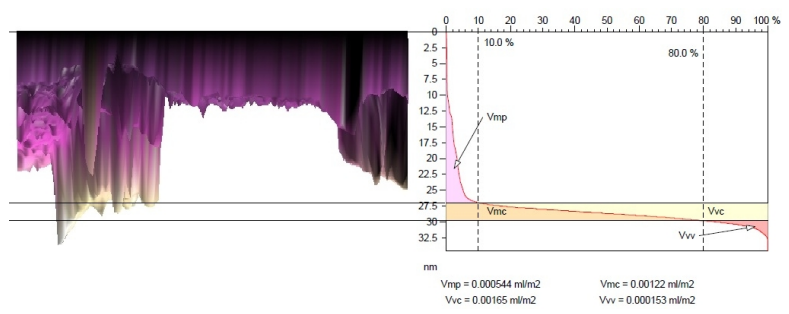

(a)

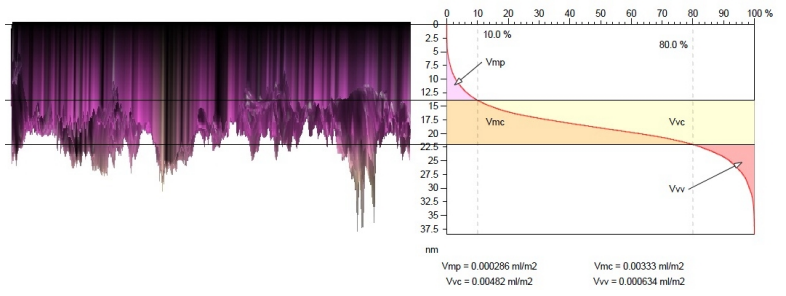

(b)

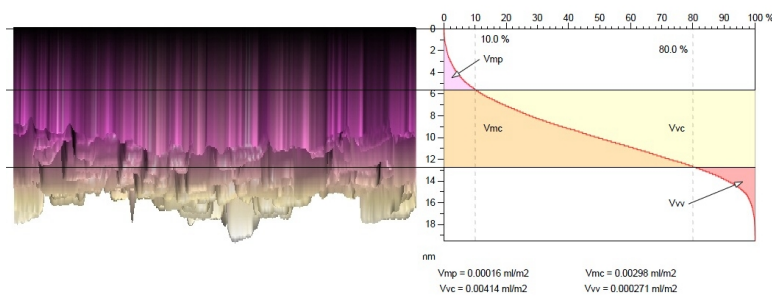

(c)

Fig. 3. Face of AFM 3-D images (left side) and graphical study of volume parameters: Vmp, Vvc, $\mathrm{Vmc}$ and $\mathrm{Vvv}$ (right side) based upon the Abbott curve calculated on the surface. Two bearing ratio thresholds are defined (using the vertical bars that are drawn with dotted lines). By default, these thresholds are set at bearing ratios of $10 \%$ and $80 \%$. The first threshold, p1 (default: $10 \%$ ), is used to define the cut level $\mathrm{c} 1$ (and $\mathrm{p} 2$ defines $\mathrm{c} 2$, respectively). AlN epilayers on sapphire substrates obtained at: (a) $1000 \mathrm{~K}$, (b) $1300 \mathrm{~K}$ and (c) $1500 \mathrm{~K}$.

\section{Discussion}

Atomic force microscopy, scanning electron microscopy and descriptive analysis have been employed to characterize the films morphology of aluminum nitride (AIN) epilayers prepared by magnetron sputtering on the sapphire substrates.

While the AFM measurements (Fig. 1) provide a surface appearance and a foundation for further mathematical processing, the SEM image (Fig. 2) shows the inner structure corresponding to AlN growth in cross-section. 
Table 1. Statistical parameters of AlN epilayers on the sapphire substrates obtained at: (a) $1000 \mathrm{~K}$, (b) $1300 \mathrm{~K}$ and (c) $1500 \mathrm{~K}$, based on ISO 25178-2:2012.

\begin{tabular}{|c|c|c|c|c|}
\hline \multirow{2}{*}{ Statistical parameters } & \multirow{2}{*}{ Symbol } & \multirow{2}{*}{$\frac{\text { Samples at } 1000 \mathrm{~K}}{\text { Values }}$} & Samples at $1300 \mathrm{~K}$ & \multirow{2}{*}{$\begin{array}{c}\text { Samples at } 1500 \mathrm{~K} \\
\text { Values }\end{array}$} \\
\hline & & & f Values & \\
\hline \multicolumn{5}{|l|}{ Height Parameters } \\
\hline Root mean square height & $\mathrm{Sq}[\mathrm{nm}]$ & 3.18 & 4.39 & 3.17 \\
\hline Skewness & Ssk $[-]$ & 4.27 & -0.089 & 0.254 \\
\hline Kurtosis & Sku $[-]$ & 26.5 & 4.27 & 2.70 \\
\hline Maximum peak height & $\mathrm{Sp}[\mathrm{nm}]$ & 28.2 & 19.1 & 9.87 \\
\hline Maximum pit height & $\mathrm{Sv}[\mathrm{nm}]$ & 6.31 & 19.4 & 9.64 \\
\hline Maximum height & $\mathrm{Sz}[\mathrm{nm}]$ & 34.5 & 38.4 & 19.5 \\
\hline Arithmetic mean height & $\mathrm{Sa}[\mathrm{nm}]$ & 1.60 & 3.24 & 2.58 \\
\hline \multicolumn{5}{|l|}{ Functional Parameters } \\
\hline Areal material ratio & Smr [\%] & 100 & 100 & 100 \\
\hline Inverse areal material ratio & Smc $[\mathrm{nm}]$ & 1.27 & 5.18 & 4.27 \\
\hline Extreme peak height & Sxp [nm] & 2.73 & 9.81 & 5.27 \\
\hline \multicolumn{5}{|l|}{ Spatial Parameters } \\
\hline Auto-correlation length & Sal $[\mu \mathrm{m}]$ & 0.290 & 0.302 & 0.135 \\
\hline Texture-aspect ratio & $\operatorname{Str}[-]$ & 0.537 & 0.696 & 0.0545 \\
\hline Texture direction & $\operatorname{Std}\left[{ }^{\circ}\right]$ & $111^{\circ}$ & $0.356^{\circ}$ & $0.363^{\circ}$ \\
\hline \multicolumn{5}{|l|}{ Hybrid Parameters } \\
\hline Root mean square gradient & $\operatorname{Sdq}[-]$ & 0.0371 & 0.0818 & 0.0866 \\
\hline Developed interfacial area ratio & $\operatorname{Sdr}[\%]$ & 0.0682 & 0.333 & 0.370 \\
\hline \multicolumn{5}{|l|}{ Functional Parameters (Volume) } \\
\hline Material volume & $\mathrm{Vm}\left[\mu \mathrm{m}^{3} / \mu \mathrm{m}^{2}\right]$ & 0.000544 & 0.000286 & 0.00016 \\
\hline Void volume & $\mathrm{Vv}\left[\mu \mathrm{m}^{3} / \mu \mathrm{m}^{2}\right]$ & 0.00181 & 0.00545 & 0.00441 \\
\hline Peak material volume & $\operatorname{Vmp}\left[\mu \mathrm{m}^{3} / \mu \mathrm{m}^{2}\right]$ & 0.000544 & 0.000286 & 0.00016 \\
\hline Core material volume & $\operatorname{Vmc}\left[\mu \mathrm{m}^{3} / \mu \mathrm{m}^{2}\right]$ & 0.00122 & 0.00333 & 0.00298 \\
\hline Core void volume & $\mathrm{Vvc}\left[\mu \mathrm{m}^{3} / \mu \mathrm{m}^{2}\right]$ & 0.00165 & 0.00482 & 0.00414 \\
\hline Pit void volume & $\operatorname{Vvv}\left[\mu \mathrm{m}^{3} / \mu \mathrm{m}^{2}\right]$ & 0.000153 & 0.000634 & 0.000271 \\
\hline \multicolumn{5}{|l|}{ Feature Parameters } \\
\hline Density of peaks & $\operatorname{Spd}\left[1 / \mu \mathrm{m}^{2}\right]$ & 0.805 & 6.44 & 4.92 \\
\hline Arithmetic mean peak curvature & $\operatorname{Spc}[1 / \mu \mathrm{m}]$ & 2.98 & 6.96 & 5.58 \\
\hline Ten point height & $\mathrm{S} 10 \mathrm{z}[\mathrm{nm}]$ & 11.5 & 19.4 & 13.2 \\
\hline Five point peak height & $\mathrm{S} 5 \mathrm{p}[\mathrm{nm}]$ & 8.10 & 12.7 & 6.86 \\
\hline Five point pit height & $\mathrm{S} 5 \mathrm{v}[\mathrm{nm}]$ & 3.40 & 6.66 & 6.33 \\
\hline Mean dale area & $\operatorname{Sda}\left[\mu \mathrm{m}^{2}\right]$ & 1.33 & 0.121 & 0.119 \\
\hline Mean hill area & Sha $\left[\mu \mathrm{m}^{2}\right]$ & 0.692 & 0.120 & 0.122 \\
\hline Mean dale volume & $\operatorname{Sdv}\left[\mu m^{3}\right]$ & 0.000317 & 0.000027 & 0.000027 \\
\hline Mean hill volume & $\operatorname{Shv}\left[\mu \mathrm{m}^{3}\right]$ & 0.000082 & 0.000033 & 0.000057 \\
\hline
\end{tabular}




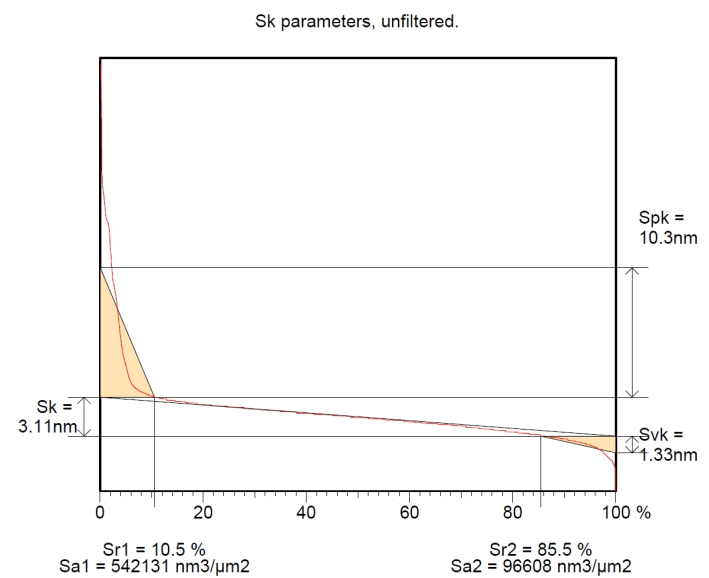

(a)

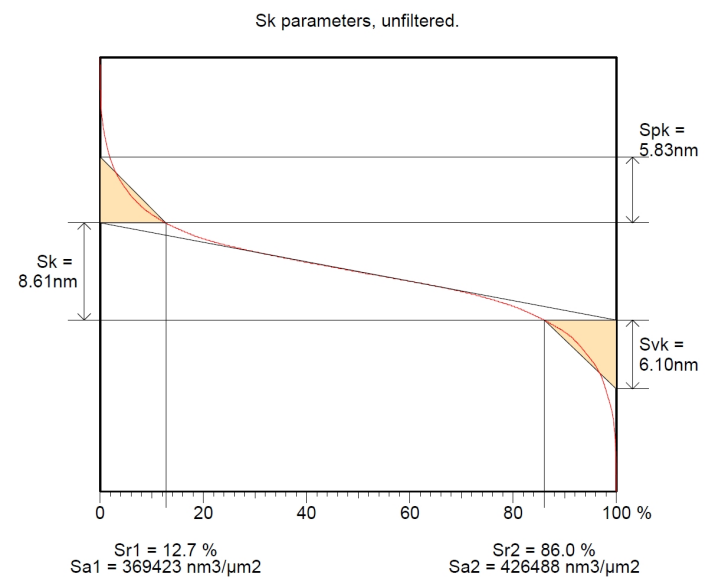

(b)

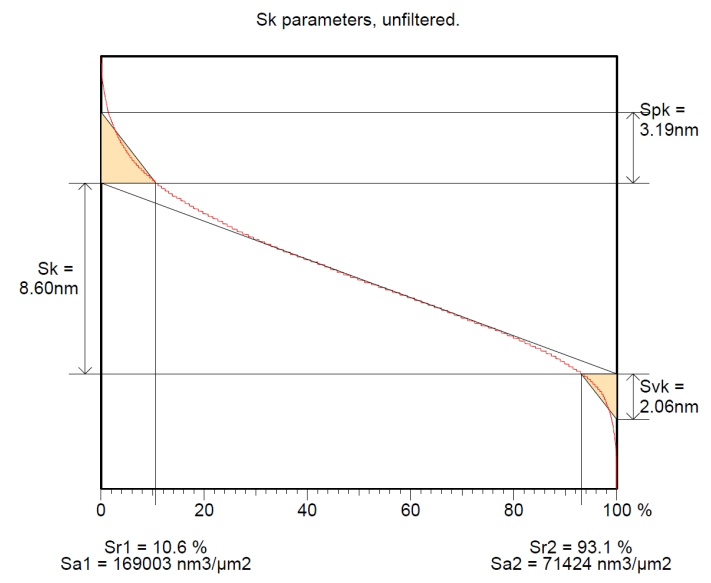

(c)

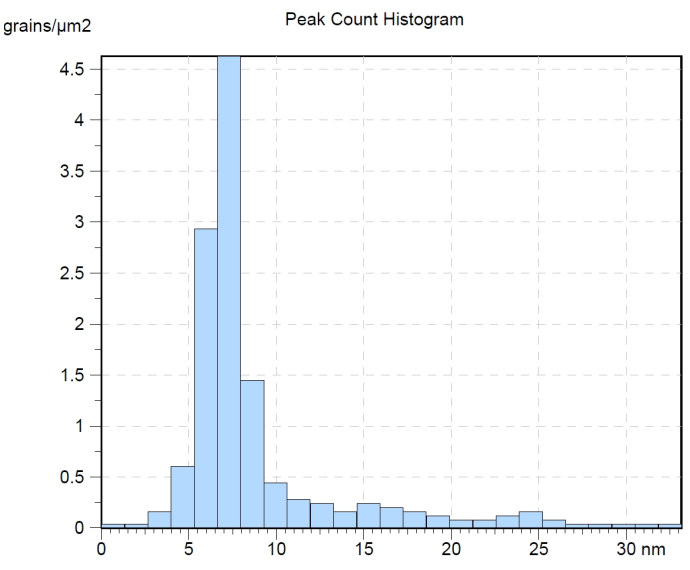

(a)

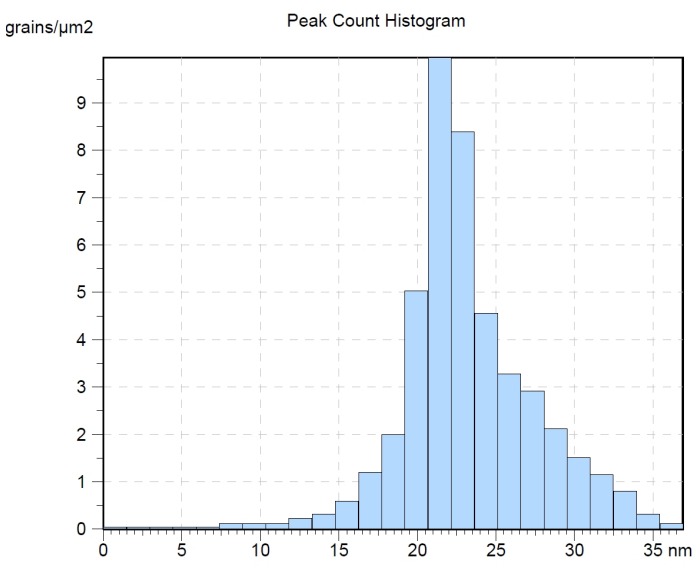

(b)

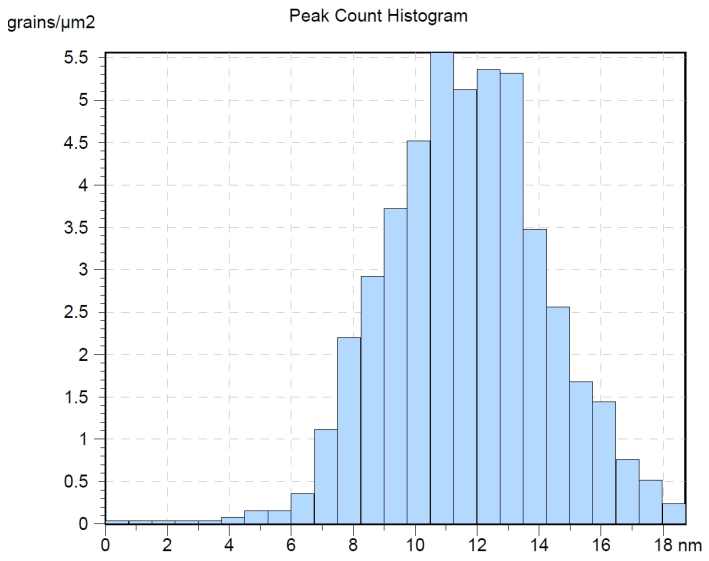

(c)
Fig. 4. Graphical study of Sk parameters for AlN epilayers on the sapphire substrates obtained at: (a) $1000 \mathrm{~K}$, (b) $1300 \mathrm{~K}$ and (c) $1500 \mathrm{~K}$.
Fig. 5. The peak count histograms for AlN epilayers on the sapphire substrates obtained at: (a) $1000 \mathrm{~K}$, (b) $1300 \mathrm{~K}$ and (c) $1500 \mathrm{~K}$. 


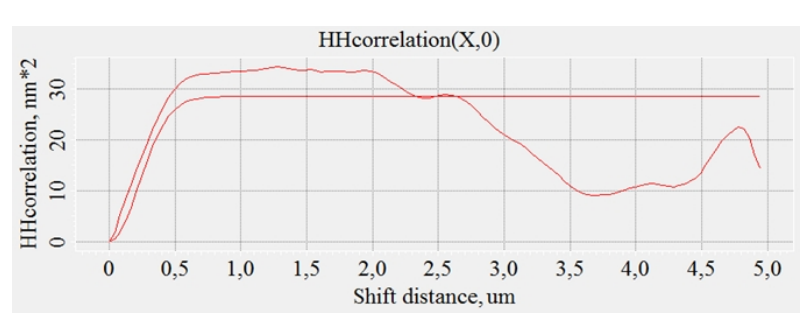

(a)

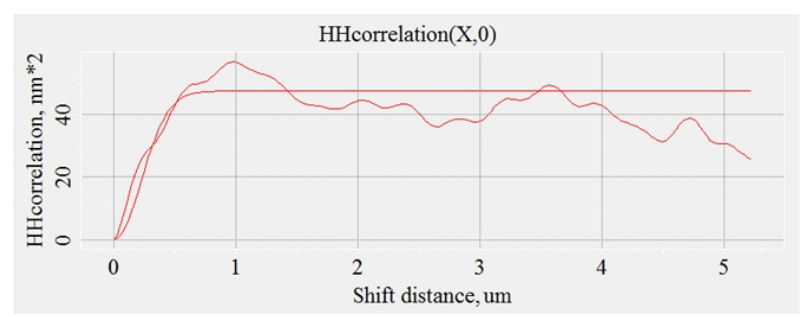

(b)

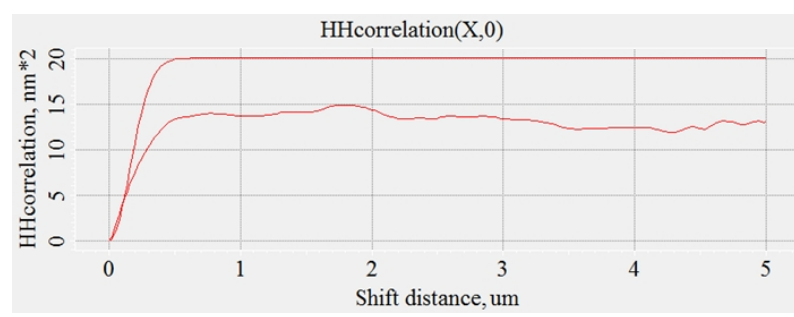

(c)

Fig. 6. The height-height correlation functions for AlN epilayers on the sapphire substrates obtained at: (a) $1000 \mathrm{~K}$, (correlation lengths: Lx $=0.319 \mu \mathrm{m}, \mathrm{Ly}=0.356 \mu \mathrm{m}$ ); (b) $1300 \mathrm{~K}$, (correlation lengths: $\mathrm{Lx}=0.317 \mu \mathrm{m}$, Ly $=$ $0.212 \mu \mathrm{m}$ ); (c) $1500 \mathrm{~K}$, (correlation lengths: Lx $=0.224 \mu \mathrm{m}, \mathrm{Ly}=0.0815 \mu \mathrm{m})$.

Different nano-asperities with a specific height probability distribution and asperity curvature for different asperity sizes are distributed over the 3-D surface of all the samples. The results show that there is an interdependence between the temperature of a substrate during deposition process and film morphology. Also, there is a connection between 3-D surface roughness parameters and the film texture (Table 1) since the texture could be considered as a measure of surface roughness [51].

The results shown in Fig. 3 and 4 include information about volume and Sk parameters. There is a decrease of Vmp and consequently Spk values. It indicates the reduction of the sudden peaks,

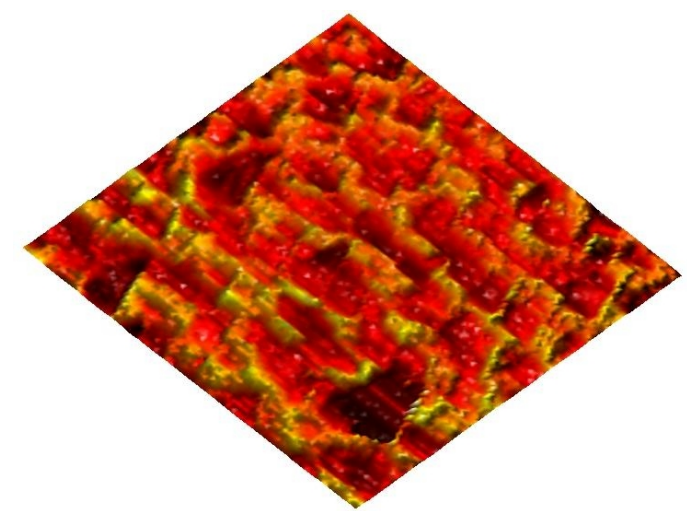

(a)

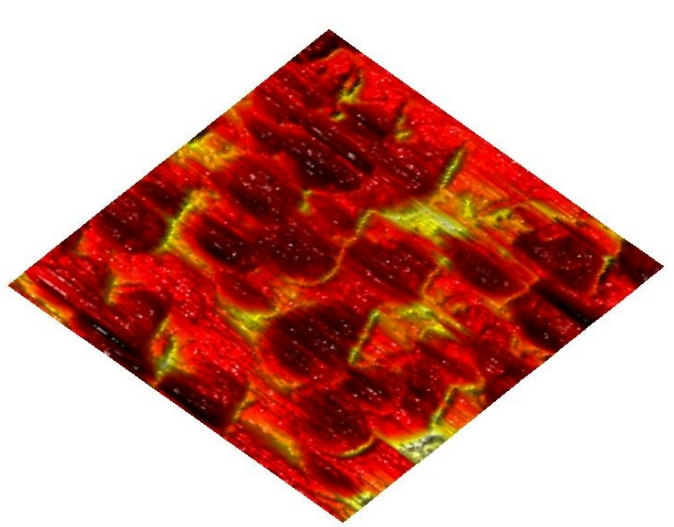

(b)

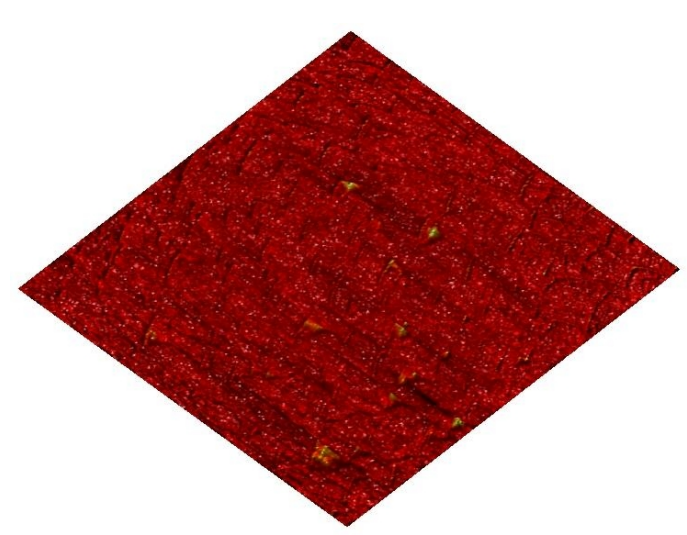

(c)

Fig. 7. AFM lateral force mode images of AlN epilayers on the sapphire substrates obtained at: (a) $1000 \mathrm{~K}$, (b) $1300 \mathrm{~K}$ and (c) $1500 \mathrm{~K}$.

and from physical point of view, it means the homogenization of grain growth. Reduced peak height to core ratio (Spk/Sk), according to the data of Fig. 4, shows increasing of texture amplitude symmetry. 
The peak count histograms (Fig. 5) show alongside with decreasing of topography heights (x-axis), the wider peaks distribution, which means that the surface features become more comparable (y-axis) in size at the highest substrate temperature.

The results show the decreasing of correlation length, caused by reduction of characteristic distance, where the correlated bonds are lost between the topography features (Fig. 6). For the higher substrate temperature during the deposition process, the film is represented by well textured areas. The same results have been obtained by Guerrero and García [25] who obtained the AlN layers by chemical vapor deposition and noted that the surface morphology became smooth with increasing of deposition temperature.

On the other hand, adhesion strength of particles and substrate depends on temperature. Increasing of temperature by heating the substrate increases the interaction at the interface at the nearsurface area.

It can be noted a strong dependence between the energetic parameters of the film growth (nucleation) and the morphology of the prepared films.

The statistical parameters of 3-D surface roughness analysis also show that the statistical description of the films is in agreement with the data obtained by Dallaeva et al. [36].

\section{Conclusions}

The statistical parameters of 3-D surface roughness have been used for the functional performance prediction and quality control of aluminum nitride (AlN) epilayers prepared by magnetron sputtering on the sapphire substrates. These results are also important for understanding the nanoscale phenomena at the contact between rough surfaces, such as the contact area, the interfacial separation, and the adhesive and frictional properties.

\section{Acknowledgements}

Research described in the paper was financially supported by the European Centre of Excellence CEITEC CZ.1.05/1.1.00/02.0068, by project Sensor, Information and Communication Systems SIX CZ.1.05/2.1.00/03.0072 as well as by grant FEKT-S-14-2240".

\section{References}

[1] Vashishta P., Kalia R.K., Nakano A., Rino J.P., J. Appl. Phys., 109 (2011), 033514:1-8.

[2] Litimein F., Bouhafs B., Dridi Z., Ruterana P., New J. Phys., 4 (2002), 64.1.

[3] Northrup J.E., Di Felice R., Neugebauer J., Phys. Rev. B, 55 (20) (1997), 13878.

[4] Kar J.P., Bose G., Aluminum Nitride (AlN) film based acoustic devices: material synthesis and device fabrication, in M.G. BEGHI (Ed.), Acoustic Waves - From Microdevices to Helioseismology, InTech, 2011, p. 563.

[5] Guda A.A., Mazalova V.L., Yalovega G.E., Soldatov A.V., J. Surf. Invest.-X-Ray+, 3 (3) (2009), 460.

[6] Ahmad M.A., Plana R., IEEE Microw. Wirel. Co., 19 (3) (2009), 140.

[7] Auger M.A., Vazquez L., Jergel M., SAnchez O., Albella J.M., Surf. Coat. Tech., 180 - 181 (2004), 140.

[8] http://www.dupont.com/products-andservices/electronic-electrical-materials/ uses-and-applications/microcircuitmaterials.html.

[9] Xiong C., Pernice W.H.P., Sun X., Schuck C., Fong K.Y., TANG H.X., New J. Phys., 14 (095014) (2012), 1.

[10] http://www. coorstek.com/resourcelibrary/library/8510-1843-Aluminum_ Nitride_Substrates.pdf.

[11] La SPINA L., NANVER L.K., Schellevis H., Iborra E., Clement M., Olivares J., ESSDERC, (2007), 354.

[12] Yoshida M., OKumiya M., IChiki R., TeKmen C., Khalifa W., Tsunekawa Y., Hara T., J. Plasma Fusion. Res., 8 (2009), 1447.

[13] Garcia-Mendez M., Morales-Rodrigues S., Machorro R., De La Cruz W., Rev. Mex. Fis, 54 (4) (2008), 271.

[14] Stafiniak A., Muszyńska D., SzyszKa A., PASZKIEWICZ B., PTASIŃSKI K., PATEla S., Paszkiewicz R., TŁaczaŁa M., Opt. Appl., 39 (4) (2009), 717.

[15] Karmann S., Schenk H.P.D., Kaiser U., FisSel A., Richter W.O., Mater. Sci. Eng. B-Adv., 50 (1997), 228.

[16] Jagannadham K., Sharma A.K., Wei Q., KALYANRAMAN R., NARAYAN J., J. Vac. Sci. Technol. A, 16 (5) (1998), 2804.

[17] Jones D.J., French R.H., Mullejans H., Loughin S., Dorneich A.D., CARCIA P.F., $J$. Mater. Res., 14 (11) (1999), 4337.

[18] IShikawa R., LUPini A.R., OBA F., Findlay S.D., Shibata N., Taniguchi T., Watanabe K., Hayashi H., SAKai T., TANaKa I., IKUhara Y., PENNYCOOK S.J., Sci. Rep.-UK, 4 (2014), 3778.

[19] Auger M.A., VÁzquez L., SÁnchez O., Jergel M., Cuerno R., Castro M., J. Appl. Phys., 97 (12) (2005), 123528. 
[20] Magnuson M., Mattesini M., Höglund C., Birch J., Hultman L., Phys. Rev. B, 80 (155105) (2009), 1.

[21] Eom D., No S.Y., Hwang C.S., KIM H.J., J. Electrochem. Soc., 153 (4) (2006), C229.

[22] Walter S., Herzog T., Heuer H., Bartzsch H., GLOESS D., Smart ultrasonic sensors systems: Investigations on aluminum nitride thin films for the excitation of high frequency ultrasound, $18^{\text {th }}$ World Conference on Nondestructive Testing, 16 - 20 April 2012, Durban, South Africa, pp.1-7.

[23] Saravanan S., Keim E.G., Krijnen G.J.M., ElWENSPOEK M., Microscopy of Semiconducting Materials, Springer Proceedings in Physics, 107 (2005), 75.

[24] Rosenberger L., BAird R., McCullen E., Auner G., Shreve G., Surf. Interface. Anal., 40 (9) (2008), 1254.

[25] Guerrero R.M., García J.R.V., Superficies y Vacio, 9 (1999), 82.

[26] Choudhary R.K., Mishra P., Biswas A., Bidaye A.C., ISRN Mater. Sci., 2013 (2013), 759462.

[27] http://ia.physik.rwth-aachen.de/research/ sputtering/www-sputter-eng . pdf.

[28] Lundin D., Sarakinos K., J. Mater. Res., 27 (5) (2012), 780 .

[29] Shon C.H., LeE J.K., Appl. Surf. Sci., $192(1-4)$ (2002), 258.

[30] Kelly P.J., ARnell R.D., Vacuum, 56 (2000), 159.

[31] http://www.nano.iisc.ernet.in/RF\% 20sputtering $\% 20$ manual_2010.pdf.

[32] SudhiR G.S., FujiI H., Wong W.S., KisielowsKi C., Newman N., Dieker C., Liliental-Weber Z., Rubin M.D., Weber E.R., J. Electron. Mater., 27 (4) (1998), 215.

[33] Nishimura M., Ishiguro T., Mater. Trans., 44 (11) (2003), 2417.

[34] Mishin S., Marx D.R., Sylvia B., Lughi V., TURner K.L., Clarke D.R., IEEE Int. Ultrason. Symposium, 2 (2003), 2028.

[35] Yoshida M., OKumiYa M., ICHiki R., Khalifa W., TEKMEN C., TSUneKawa Y., HaRA T., TANAKa K., Plasma Process Polym., 6 (2009), S310-S313.
[36] Dallaeva D.S., Bilalov B.A., Gitikchiev M.A., Kardashova G.D., SAFaraliev G.K., TOMÁneK P., ŠKarvada P., Smith S., Thin Solid Films, 526 (2012), 92.

[37] Hass G., Thun R.F., Physics of thin films, Academic Press: New York, London, 1964, p. 396.

[38] http://www.ntmdt.ie/data/media/files/ accessories/afm_probes_accessories_ catalogue.pdf.

[39] BhushaN B., Introduction to Tribology, $2^{\text {nd }}$ Ed., John Wiley \& Sons Ltd., New York, 2013.

[40] ŢĂLU Ş., Ph.D. Thesis: Researches concerning the cold rolling process of external cylindrical threads, The Technical University of Cluj-Napoca, Faculty of Machine Building, Romania, 1998.

[41] Cîrstoiu C.A., The Romanian Review Precision Mechanics, Optics \& Mechatronics, 38 (2010), 163.

[42] Raoufi D., Hosseinpanahi F., J. Mod. Phys., 3 (8) (2012), 645.

[43] ŢăLU Ş., Ghazai A.J., Stach S., Hassan A., HasSAN Z., ŢĂLU M., J. Mater. Sci.-Mater. El., 25 (1) (2014), 466.

[44] ŢăLU Ş., Marković Z., Stach S., Marković B.T., ŢĂLU M., Appl. Surf. Sci., 289 (2014), 97.

[45] ŢăLu Ş., Stach S., MÉndez A., Trejo G., Ţălu M., J. Electrochem. Soc., 161 (2014), D44.

[46] Ţălu Ş., Stach S., Mahajan A., PathaK D., WaGNER T., Kumar A., BEDI R.K., ŢĂLU M., Electron. Mater. Lett., 10 (4) (2014), 719.

[47] Ţălu Ş., Stach S., Mahajan A., Pathak D., WagNER T., Kumar A., Bedi R.K., Surf. Interface. Anal., 46 (6) (2014), 393.

[48] http://www.iso.org/iso/catalogue_detail. htm? csnumber $=42785$.

[49] http://www.digitalsurf.fr/en/mntspm.html.

[50] http://www.graphpad.com/scientificsoftware/instat/.

[51] Russ C.J., The image processing handbook, $4^{\text {th }}$ Ed. CRC Press, Raleigh, North Carolina, 2002, p. 258.

Received 2014-09-02

Accepted 2014-12-01 